\title{
9 DNA nanotechnology: new adventures for an old warhorse
}

$$
\text { Bijan Zakeri }{ }^{1,2 *} \text { and Timothy K. Lu }{ }^{1,2 *}
$$

11 Department of Electrical Engineering and Computer Science, Department of

12 Biological Engineering, Research Laboratory of Electronics, Massachusetts Institute of

14 2MIT Synthetic Biology Center, 500 Technology Square, Cambridge MA 02139, USA

15

16 *Correspondence to Bijan Zakeri (bijan.zakeri@oxfordalumni.org) and Timothy K. Lu

17 (timlu@mit.edu).

18

19

20

21

22

23

24 
As the blueprint of life, the natural exploits of DNA are admirable.

26 However, DNA should not only be viewed within a biological context. It is an

27 elegantly simple yet functionally complex chemical polymer with properties

28 that make it an ideal platform for engineering new nanotechnologies. Rapidly advancing synthesis and sequencing technologies are enabling novel unnatural applications for DNA beyond the realm of genetics. Here we explore

31 the chemical biology of DNA nanotechnology for emerging applications in communication and digital data storage. Early studies of DNA as an alternative to magnetic and optical storage mediums have not only been promising, but

34 have demonstrated the potential of DNA to revolutionize the way we interact with digital data in the future.

DNA wears many hats. Yet our common conception of DNA is largely centered on its role in genetics. After all, nature has used DNA to store biological information for billions of years, entrusting it with some great secrets brought to light by the discovery of the structure of DNA by Watson and Crick [1]. However, the landscape of biology has dramatically changed over the past half-century. While in the past we were limited to only observing biology from a distance, we are now able to directly manipulate and synthesize biological components for non-biological 43 applications.

DNA nanotechnology has been largely viewed in terms of the self-assembly of DNA molecules to form nanostructures (see recent reviews [2-4]). Traditionally,

46 proteins are considered to be the molecular scaffolds of nature and have been

47 adapted for genetically encodable molecular self-assembly [5]. Yet the coordinated

48 base pairing of nucleotides and advances in DNA synthesis have been exploited for

49 using DNA as a structural scaffold rather than a storage molecule of genetic

50 information, leading to the construction of programmable and complex self-

51 assembling 3D architectures [6-8].

52 The chemical synthesis of DNA for creating synthetic genomes and

53 developing unnatural genetic alphabets has also been hallmarks of DNA

54 nanotechnology (see recent reviews [9-11]). These synthetic biology approaches 
55 can allow us to probe abiogenesis, shedding light on the origins of life [12]. To

56 illustrate, recent studies have demonstrated an ability to expand the genetic

57 alphabet beyond A, G, C, and T in living cells [13], or have employed synthetic

58 genetic polymers to develop new catalysts called XNAzymes [14].

59 Here we review new and emerging applications for DNA outside of a

60 biological context. Billions of years of evolution have optimized DNA as an efficient

61 biopolymer for data transmission and storage within cells, between species, and

62 across generations. With rapidly declining synthesis costs [15] and emerging

63 portable sequencing technology [16-18], synthetic DNA appears as an attractive

64 chemical polymer for future applications in digital data communication and storage.

65

66 Digital data: challenges and opportunities

67 Over the past several decades, we have witnessed revolutionary changes in

68 how we transmit, process, and consume information. Digital and online data

69 communication and storage have provided great speed and convenience, yet they

70 have also raised important concerns regarding capacity and security. Everyday we

71 produce ever-increasing amounts of digital information using writing, reading, and

72 storage technologies that are rapidly evolving. As our personal and professional

73 information is increasingly in a vulnerable digital space, security must also be at the

74 forefront of our thoughts. In order to be able to access our information in the future,

75 we must ask ourselves:

$76 \quad$ i. What is the most efficient way to store this information?

77 ii. How secure is the stored data against intervention by unauthorized

$78 \quad$ individuals?

79 iii. How stable is the data storage platform?

80 iv. How easy is it to reproduce-copy \& paste-the data?

$81 v$. How will we read and re-write the information in future years when the

82 technologies used to write the original information no longer exist? 
As we consider the next revolutionary technological advancement in

84 communication and data storage, key attributes of DNA for information storage

85 warrant further consideration (Figure 1) [19,20]:

86 i. High-density data storage: DNA has 1,000,000-fold higher data storage 87 capacity than current commercial magnetic and optical platforms [21].

88 ii. Static data maintenance: Data maintained in synthetic DNA represents a 89 static offline system that is not subject to undesired sequence change or 90 evolution, and it cannot be accessed remotely using the Internet.

91 iii. Stability: DNA can be stably maintained for millennia, with a fossilized bone 92 half-life of 521 years [22] and the oldest sequenced complete genome being 93 from an ancient horse living 560,000-780,000 years ago [23]. Furthermore, 94 accelerated aging experiments predict digital data in DNA can be recovered

96 iv. Reproducibility: Encoded data can be rapidly, cost-effectively, and with an estimated 2013 global digital content of 4.4 ZB, set to increase to $44 \mathrm{ZB}$ by

1072020 [25]. This continuous generation of knowledge must be preserved to ensure 108 future generations have access to the information, and that knowledge is not lost in 109 time [26-28]. In this context, DNA is actively used to provide a window in to our 110 biological past, whether allowing us to read the history of hominin evolution [29], 111 identifying the 530-year-old remains of a king killed in battle [30], or tracking the 
112 early spread of HIV in humans [31], it gives us access to information archived for us

113 by previous generations.

\section{DNA Communication}

116 DNA communication is best for niche applications, where security is more

117 important than speed. The transfer of information to DNA is currently time

118 consuming, laborious, and expensive. However, in addition to being able to contain

119 and transmit encrypted information similar to digital communication mediums,

120 DNA is also invisible to the naked eye and data extraction requires skills in

121 molecular biology. This makes DNA a discreet communication channel that can

122 provide the highest levels of security [32,33]. Furthermore, information can be

123 incorporated in both the direct sequence and the 3D architecture of assembled DNA

124 molecules.

125 In 1999, Bancroft and colleagues were the first to demonstrate the concept of

126 using DNA for communication [34]. Their proof-of-concept experiment was

127 designed to initiate a discussion on the additional security that could be afforded to

128 communication channels by integration of molecular biology techniques. They

129 constructed a substitution table-based encryption key to encode "JUNE 6 INVASION:

130 NORMANDY" that was further secured with steganography - the art of concealing

131 information amongst other different information - by mixing with non-coding DNA.

132 The DNA message was then stored in a printed microdot, posted in the mail, and

133 read via PCR amplification and sequencing.

134 Information can also be embedded in the artificial 3D architectures of

135 programmed and self-assembled DNA [35]. For instance, Mao et al. constructed DNA

136 tiles composed of four DNA molecules that assembled into three double helices [33].

137 Individual tiles possessed sticky ends that contained information to direct further

138 assembly with other tiles, thereby allowing cumulative XOR computation, where

139 two identical bits produce an output of 0 and two different bits produce an output of

1401 [36]. For example, if two DNA tiles representing 0 combine then they produce an 
141 output of 0 , similarly if two tiles are 1 then the output is 0 , and if one tile is 0 and the

142 other is 1 then the output is 1 . This method can be used for executing unbreakable

143 one-time pad encryption $[32,37,38]$. A one-time pad is an encryption key that is

144 random and is only used once. Therefore, if one wants to encrypt the data 0110110

145 with one-time pad XOR computation, then they can randomly generate an

146 encryption key such as 1001011, and executing this key on the original data will

147 produce the encrypted information 1111101 , which can only be decrypted with the

148 single-use encryption key.

149 DNA can also be used for communicating the identity of products for

150 biosecurity applications $[39,40]$. Genetic modification of organisms has become a

151 routine procedure [41], and there is interest in establishing rapid identification

152 methods in case they are environmentally released. One simple method would be

153 through standardized watermarking of genetically engineered organisms [42,43].

154 Furthermore, DNA barcoding can serve as a valuable method for tracking food and

155 agricultural products for authentication and safety concerns [44].

\section{Long-Term Data Storage in DNA}

158 The high capacity and chemical stability of DNA make it an ideal platform for

159 long-term data storage. Yet high writing and reading costs mean that DNA storage is

160 best for infrequently accessed information that needs to be available to future

161 generations.

162 To demonstrate the potential of DNA for storing a large volume of data,

163 Church and colleagues encoded a book containing 53,426 words and 11 images in

164 DNA, totaling $659 \mathrm{kB}$ [21]. The digital html file was converted from bits to bases by

165 substitution, where $0=\mathrm{A}$ or $\mathrm{C}$ and $1=\mathrm{T}$ or $\mathrm{G}$ (Figure 2). Stretches of homopolymers

166 represent a technical challenge in synthesis and sequencing procedures, resulting in

167 increased rates of error [45]. Therefore, for engineering reasons the authors

168 disallowed homopolymeric stretches of 4 or more. With these considerations, the

169 data was encoded in 159 nt oligonucleotides printed on DNA microchips utilizing a 
170 total of 54,898 oligonucleotides, where each contained a $96 \mathrm{nt}$ data region, a $19 \mathrm{nt}$

171 barcode, and a $22 \mathrm{nt}$ sequence used for writing (amplification) and reading

172 (sequencing). This represented a data storage density of $5.5 \times 10^{15} \mathrm{bits} / \mathrm{mm}^{3}$, far

173 greater than a conventional hard disk with a capacity of $3.1 \times 10^{9} \mathrm{bits} / \mathrm{mm}^{3}$. The

174 book was then read using next-generation sequencing followed by data assembly.

175 Goldman and colleagues went a step further and stored ASCII text, PDF, JPEG, 176 and MP3 file formats in DNA, totaling $757 \mathrm{kB}$ [46]. By encoding the complete set of

177 Shakespearian sonnets, a scientific paper, a picture, the recording of a famous

178 speech, and the Huffman code that was used to convert the digital files to bases and

179 then shipping the DNA around the world under standard conditions, the authors

180 demonstrated the versatility of DNA for not only information storage but also for

181 stability under everyday handling conditions. Furthermore, the Goldman study used

182 trits to convert bits to bases and in the process excluded homopolymeric runs. Trits

183 are base- 3 digits composed of 0,1 , and 2 . Therefore instead of encoding bytes based

184 on binary code ( 0 and 1 ), they developed software to encode all of the 256 possible

185 bytes using 5 or 6 unique trits (represented by nucleotides). For example, the

186 character 'a' was converted to '01112' in trits, which was then encoded as 'GAGAT'

187 in DNA. Overall, the study used a total of 153,335 strings of $117 \mathrm{nt}$ to provide four-

188 fold coverage of all of the encoded data, with estimated costs of $\$ 12,400 / \mathrm{MB}$ for

189 writing and $\$ 220 / \mathrm{MB}$ for reading.

190 Recently, Grass and colleagues addressed two important concerns related to

191 DNA data storage-error correction and chemical preservation methods-while

192 encoding $83 \mathrm{kB}$ of text into 4991 DNA strands of $158 \mathrm{nt}$ [24]. Briefly, Reed-Solomon

193 error-correcting codes were adapted to a DNA codon wheel to introduce encoding

194 redundancy that provided error tolerance. The conversion of digital information

195 into bases was also structured to ensure homopolymeric runs of more than three

196 bases were not possible. Furthermore, they compared the robustness of four

197 different storage methods of DNA: (i) dried, (ii) infused in filter paper, (iii) in a

198 biopolymer mimicking conditions in seeds and spores, and (iv) encapsulated in a

199 silica sphere. Following accelerated aging experiments, silica spheres provided the 
most robust storage condition. This was likely the result of reduced exposure to

201 water as silica provides a physical inorganic barrier between DNA and water,

202 thereby reducing the local humidity around DNA and aiding in long-term stability.

203 Based on their error-correction and silica storage methods, the authors estimated

204 that digital data stored in DNA could be recovered error-free following archiving in

205 permafrost conditions for more than 2 million years.

\section{Future Outlook}

208 DNA holds great promise for meeting our future data storage needs.

209 However, much further research is still required to establish it as a legitimate

210 storage medium. Many opportunities exist for innovation, such as incorporating

211 XNA technology into chemical synthesis methods to increase the DNA alphabet, or

212 developing DNA-specific cryptography and steganography methodologies for

213 increasing information security [47-49]. However, key limitations that need to be

214 addressed before DNA storage can be more broadly adopted are (Figure 3):

215 i. Sequencing obfuscation: What if we would like to keep our data in DNA and

216 let it be easily read (sequenced) by authorized individuals, but obfuscate

217 sequencing attempts by unauthorized individuals as a means of physical

218 security? Can we camouflage DNA?

219 ii. DNA language: Can we develop a unique DNA language with insights from

220 biology, computer science, and linguistics that is purpose built for encoding

221 digital information in DNA?

222 iii. Write/read cost: Can we adapt DNA write/read technologies specifically for 223 data storage-instead of conventional biological applications-to maximize 224 efficiency?

225 iv. Write/read speed: Can we adapt write/read technologies to be purely based 226 on chemistry-instead of using sensitive enzymes - to allow for fast and 227 robust in-field functionality? 
DNA has the potential be a disruptive technology that can dramatically change the digital storage landscape. With further research to address key concerns,

230 then that old warhorse DNA can embark on yet another exciting adventure.

232 Acknowledgements This work is sponsored by the Defense Advanced Research

233 Projects Agency under Air Force Contract \#FA8721-05-C-0002, and NIH grants 234 1R01EB017755, 1DP2OD008435, and 1P50GM098792.

235

\section{References}

237 Papers of particular interest, published within the period of review, have been

238 highlighted as:

$239 *$ of special interest

$240 * *$ of outstanding interest

241 1. Watson JD, Crick FH: Molecular structure of nucleic acids; a structure for

242 deoxyribose nucleic acid. Nature 1953, 171:737-738.

243 2. Saaem I, LaBean TH: Overview of DNA origami for molecular self-

244 assembly. Wiley Interdiscip Rev Nanomed Nanobiotechnol 2013, 5:150-162.

$2453 . \quad$ Tintoré M, Eritja R, Fábrega C: DNA nanoarchitectures: steps towards

246 biological applications. Chembiochem 2014, 15:1374-1390.

247 4. Bell NAW, Keyser UF: Nanopores formed by DNA origami: a review. FEBS

248 Lett 2014, 588:3564-3570.

249 5. Veggiani G, Zakeri B, Howarth M: Superglue from bacteria: unbreakable

250 bridges for protein nanotechnology. Trends Biotechnol. 2014, 32:506-512.

251 6. Buckhout-White S, Spillmann CM, Algar WR, Khachatrian A, Melinger JS,

252 Goldman ER, Ancona MG, Medintz IL: Assembling programmable FRET-based

253 photonic networks using designer DNA scaffolds. Nat Commun 2014, 5:5615.

2547 7an K, Kim D-N, Zhang F, Adendorff MR, Yan H, Bathe M: Lattice-free

255 prediction of three-dimensional structure of programmed DNA assemblies.

256 Nat Commun 2014, 5:5578.

257 8. Bai X-C, Martin TG, Scheres SHW, Dietz H: Cryo-EM structure of a 3D DNA-

258 origami object. Proc Natl Acad Sci USA 2012, 109:20012-20017.

259 9. Pinheiro VB, Holliger P: The XNA world: progress towards replication and

260 evolution of synthetic genetic polymers. Curr Opin Chem Biol 2012, 16:245-252.

261 10. Pinheiro VB, Holliger P: Towards XNA nanotechnology: new materials

262 from synthetic genetic polymers. Trends Biotechnol 2014, 32:321-328.

263 11. Pál C, Papp B, Pósfai G: The dawn of evolutionary genome engineering. 
Nat Rev Genet 2014, 15:504-512.

265 12. Attwater J, Holliger P: A synthetic approach to abiogenesis. Nat Methods 2014, 11:495-498. 13. Malyshev DA, Dhami K, Lavergne T, Chen T, Dai N, Foster JM, Corrêa IR, Romesberg FE: A semi-synthetic organism with an expanded genetic alphabet. Nature 2014, 509:385-388.

14. Taylor AI, Pinheiro VB, Smola MJ, Morgunov AS, Peak-Chew S, Cozens C, Weeks KM, Herdewijn P, Holliger P: Catalysts from synthetic genetic polymers. Nature 2015, 518:427-430.

15. Carr PA, Church GM: Genome engineering. Nat Biotechnol 2009, 27:11511162.

16. Stoddart D, Heron AJ, Mikhailova E, Maglia G, Bayley H: Single-nucleotide discrimination in immobilized DNA oligonucleotides with a biological nanopore. Proc Natl Acad Sci USA 2009, 106:7702-7707.

17. Jain M, Fiddes IT, Miga KH, Olsen HE, Paten B, Akeson M: Improved data analysis for the MinION nanopore sequencer. Nat Methods 2015, 12:351-356. 18. Ashton PM, Nair S, Dallman T, Rubino S, Rabsch W, Mwaigwisya S, Wain J, $O$ 'Grady J: MinION nanopore sequencing identifies the position and structure of a bacterial antibiotic resistance island. Nat Biotechnol 2015, 33:296-300. *Demonstration of the portable MinION sequencer. 19. Cox JP: Long-term data storage in DNA. Trends Biotechnol 2001, 19:247250.

20. Bancroft C, Bowler T, Bloom B, Clelland CT: Long-term storage of information in DNA. Science 2001, 293:1763-1765.

21. Church GM, Gao Y, Kosuri S: Next-generation digital information storage in DNA. Science 2012, 337:1628.

** Demonstrated the potential of data archiving in DNA by encoding a complete book and 11 images in DNA.

22. Allentoft ME, Collins M, Harker D, Haile J, Oskam CL, Hale ML, Campos PF, Samaniego JA, Gilbert MTP, Willerslev E, et al.: The half-life of DNA in bone: measuring decay kinetics in 158 dated fossils. Proc R Soc Lond B: Biol Sci 2012, 279:4724-4733.

23. Orlando L, Ginolhac A, Zhang G, Froese D, Albrechtsen A, Stiller M, Schubert M, Cappellini E, Petersen B, Moltke I, et al.: Recalibrating Equus evolution using the genome sequence of an early Middle Pleistocene horse. Nature 2013, 499:74-78.

24. Grass RN, Heckel R, Puddu M, Paunescu D, Stark WJ: Robust chemical preservation of digital information on DNA in silica with error-correcting codes. Angew Chem Int Ed Engl 2015, 54:2552-2555.

** Developed an error-proof encoding method and performed accelerated aging experiments with DNA containing digital data.

25. EMC: The Digital Universe of Opportunities. Infobrief 2014, 1-17.

* Market report analyzing the global digital data landscape.

26. Lynch C: Big data: How do your data grow? Nature 2008, 455:28-29.

27. Berman F: Got Data?: A Guide to Data Preservation in the Information Age. Commun ACM 2008, 51:50-56. 
$31028 . \quad$ Beagrie N: Digital Curation for Science, Digital Libraries, and Individuals.

311 Int J Digit Curation 2006, 1:3-16.

312 29. Prüfer K, Racimo F, Patterson N, Jay F, Sankararaman S, Sawyer S, Heinze A,

313 Renaud G, Sudmant PH, de Filippo C, et al.: The complete genome sequence of a

314 Neanderthal from the Altai Mountains. Nature 2014, 505:43-49.

315 30. King TE, Fortes GG, Balaresque P, Thomas MG, Balding D, Delser PM,

316 Neumann R, Parson W, Knapp M, Walsh S, et al.: Identification of the remains of

317 King Richard III. Nat Commun 2014, 5:5631.

318 31. Faria NR, Rambaut A, Suchard MA, Baele G, Bedford T, Ward MJ, Tatem AJ,

319 Sousa JD, Arinaminpathy N, Pépin J, et al.: The early spread and epidemic ignition

320 of HIV-1 in human populations. Science 2014, 346:56-61.

321 32. Gehani A, LaBean TH, Reif JH: DNA-based Cryptography. Discr Math Theor

322 Comput Sci 2000, 54:233-249.

323 33. Mao C, LaBean TH, Reif JH, Seeman NC: Logical computation using

324 algorithmic self-assembly of DNA triple-crossover molecules. Nature 2000,

325 407:493-496.

326 34. Clelland CT, Risca V, Bancroft C: Hiding messages in DNA microdots.

327 Nature 1999, 399:533-534.

328 35. Halvorsen K, Wong WP: Binary DNA nanostructures for data encryption.

329 PloS One 2012, 7:e44212.

330 36. Yan H, Feng L, LaBean TH, Reif JH: Parallel Molecular Computations of

331 Pairwise Exclusive-Or (XOR) Using DNA "String Tile" Self-Assembly. J Am Chem

332 Soc 2003, 125:14246-14247.

333 37. Ekert A, Renner R: The ultimate physical limits of privacy. Nature 2014,

$334 \quad \mathbf{5 0 7}: 443-447$.

335 38. Hirabayashi M, Kojima H, Oiwa K: Effective algorithm to encrypt

336 information based on self-assembly of DNA tiles. Nucleic Acids Symp Ser (Oxf)

337 2009, 53:79-80.

338 39. Hebert PDN, Dewaard JR, Zakharov EV, Prosser SWJ, Sones JE, McKeown JTA,

339 Mantle B, La Salle J: A DNA "barcode blitz": rapid digitization and sequencing of

340 a natural history collection. PloS One 2013, 8:e68535.

341 40. Haughton D, Balado F: BioCode: two biologically compatible Algorithms

342 for embedding data in non-coding and coding regions of DNA. BMC

343 Bioinformatics 2013, 14:121.

344 41. Annaluru N, Muller H, Mitchell LA, Ramalingam S, Stracquadanio G,

345 Richardson SM, Dymond JS, Kuang Z, Scheifele LZ, Cooper EM, et al.: Total synthesis

346 of a functional designer eukaryotic chromosome. Science 2014, 344:55-58.

347 42. Gibson DG, Glass JI, Lartigue C, Noskov VN, Chuang RY, Algire MA, Benders

348 GA, Montague MG, Ma L, Moodie MM, et al.: Creation of a bacterial cell controlled

349 by a chemically synthesized genome. Science 2010, 329:52-56.

350 43. Liss M, Daubert D, Brunner K, Kliche K, Hammes U, Leiherer A, Wagner R:

351 Embedding permanent watermarks in synthetic genes. PloS One 2012, 7:

352 e42465.

353 44. Bloch MS, Paunescu D, Stoessel PR, Mora CA, Stark WJ, Grass RN: Labeling

354 milk along its production chain with DNA encapsulated in silica. J Agric Food

355 Chem 2014, 62:10615-10620. 
35645 . Voelkerding KV, Dames SA, Durtschi JD: Next-generation sequencing: from 357 basic research to diagnostics. Clin Chem 2009, 55:641-658.

358 46. Goldman N, Bertone P, Chen S, Dessimoz C, LeProust EM, Sipos B, Birney E:

359 Towards practical, high-capacity, low-maintenance information storage in

360 synthesized DNA. Nature 2013, 494:77-80.

$361{ }^{* *}$ A comprehensive study and cost analysis of data storage in DNA. Encoded ASCII

362 text, PDF, JPEG, and MP3 files in DNA.

363 47. Tulpan D, Regoui C, Durand G, Belliveau L, Leger S: HyDEn: a hybrid

364 steganocryptographic approach for data encryption using randomized error-

365 correcting DNA codes. BioMed Res Int 2013, 2013:634832.

366 48. Heider D, Barnekow A: DNA-based watermarks using the DNA-Crypt

367 algorithm. BMC Bioinformatics 2007, 8: 176.

368 49. Kawano T: Run-length encoding graphic rules, biochemically editable

369 designs and steganographical numeric data embedment for DNA-based

370 cryptographical coding system. Commun Integr Biol 2013, 6: e23478.

371

372

373

374

375

376

377

378

379

380

381

382

383

384

385

386 


\section{$387 \quad$ Figure 1}

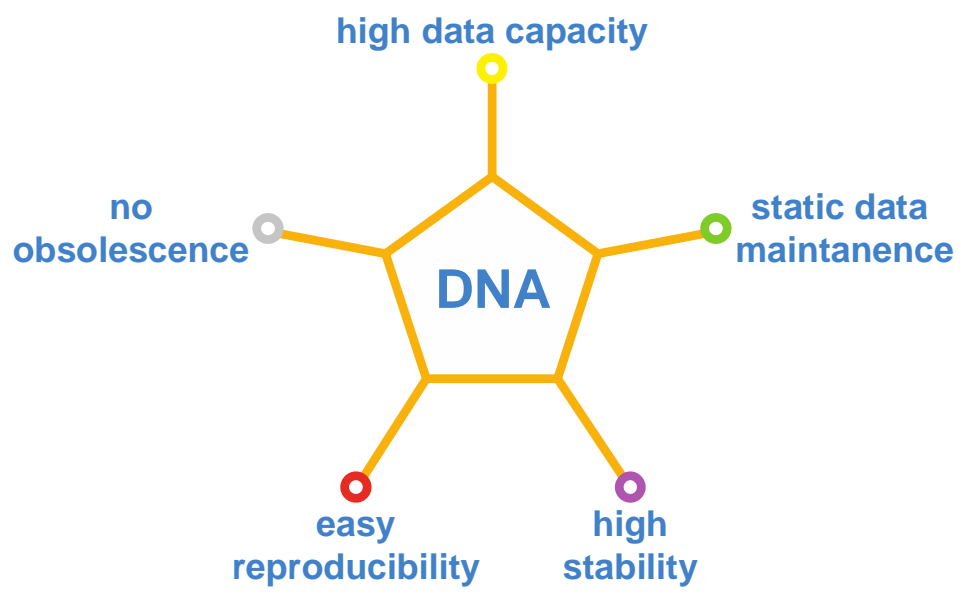

388

389 Figure 1. Key attributes of DNA for long-term data archiving.

390

391

392

393

394

395

396

397

398

399

400

401

402

403 


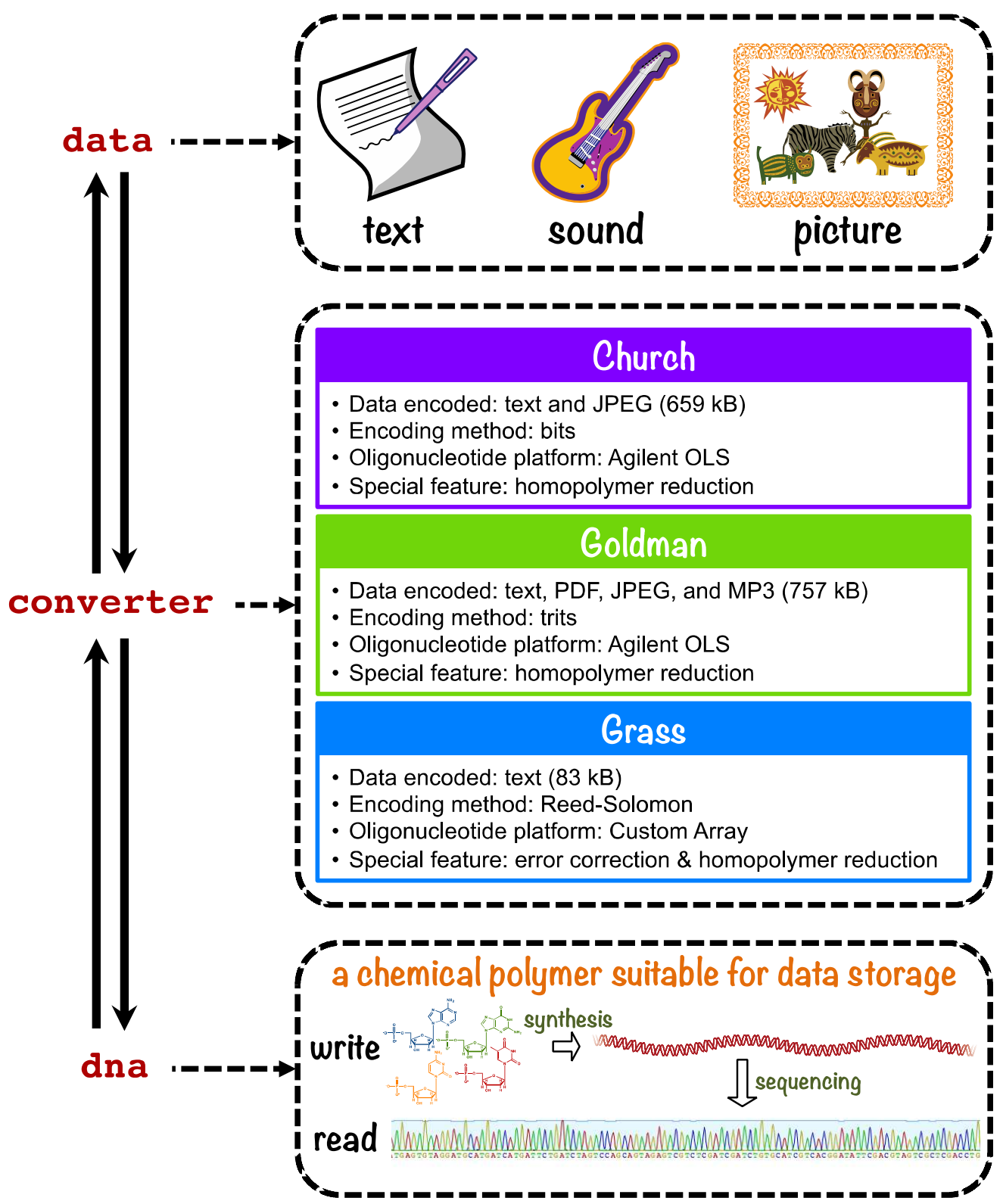

406 Figure 2. Conversion of data from a digital format $(0 / 1)$ to a DNA format

407 (A/G/C/T). The Church [20], Goldman [42], and Grass [23] studies all employed

408 different methods to encode information in DNA, but they all achieved reliable data 409 storage. 
412 Figure 3

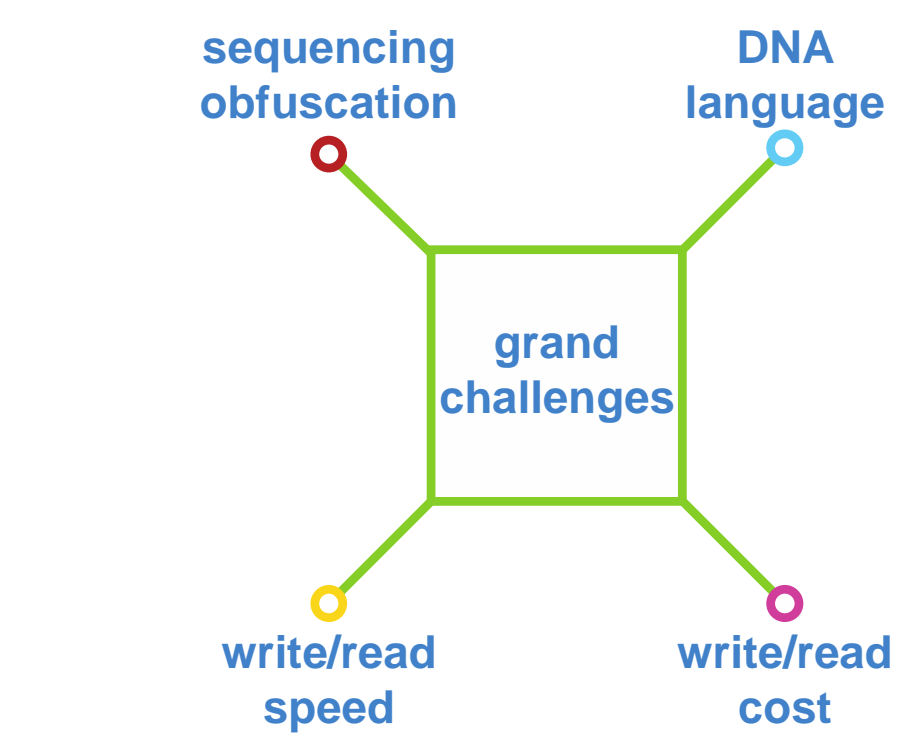

413

414 Figure 3. Grand challenges that should be addressed in order to realize the 415 potential of DNA for long-term data archiving. 